\begin{tabular}{|c|c|}
\hline \multirow{3}{*}{ 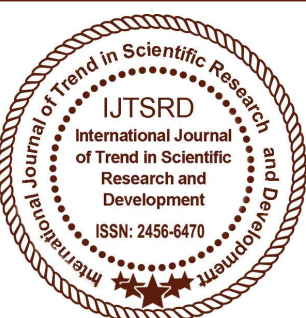 } & $\begin{array}{l}\text { International Journal of Trend in Scientific } \\
\text { Research and Development (IJTSRD) }\end{array}$ \\
\hline & International Open Access Journal \\
\hline & ISSN No: 2456 - 6470 | www.ijtsrd.com | Volume - 2 | Issue -3 \\
\hline
\end{tabular}

\title{
Review on Tri Band Antenna for Remote Sensing Applications
}

\author{
Priya Kumari \\ Department of Electronics and Communication Engineering, \\ L.J. Institute of Engineering \& Technology, Ahmedabad, Gujarat, India
}

\section{ABSTRACT}

In recent year microstrip antenna has attracted more attention over a conventional antenna mainly because of their simple design, variety of shape, light weight, low profile and low cost. In this review paper different techniques are available to obtain a tri-band performance from a microstrip antenna.

Keywords: Return loss, antenna gain, microstrip, GNSS

\section{INTRODUCTION}

The rapidly growing wireless communication applications demand antenna that are low profile, light weight, and low cost. In all of the available pool of antennas, microstrip patch antennas have been well suited for wireless communication [1]. The increasing number of wireless standards and device technology improvement are placing a high demand for multiple antenna. While using multiple antenna can achieve multiband operation it increases the cost and complexity of the system. In addition, using multiple antenna creates the coupling problem which in turn degrades the performance of antenna. An alternative solution is to modify the antenna such that it can be used for multiband wireless communication[2].

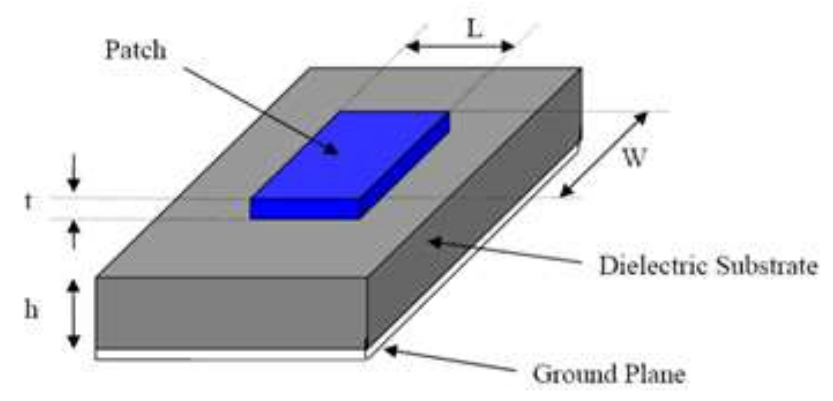

Figure 1: Structure of microstrip patch antenna

\section{BACKGROUND}

The global navigation satellite system (GNSS) is a service that enables high accuracy position with the help of satellite signals. The application which is under constant development now a day is GNSS reflectometry. Using the reflected GNSS signals from the land and ocean surface, sea ice sensing and the extraction of land surface topography and near surface soil moisture and near surface soil moisture are being done with proper calibration.

In addition, surface multi-path is one of main error sources for GNSS navigation and positioning. It has recently been recognized however that the special kind of GPS multipath delay reflected from the earth's surface environment. A recent interesting result on fluctuations in near surface soil moisture has been successfully retrieved from the ground GNSS multipath, fairly matching, soil moisture fluctuations in soil measured with conventional sensors. The space-born GNSS receiver delay of the GNSS reflected signal with respect to the rough surface could provide information of the differential signal with respect to the rough surface could provide information on differential path between direct and reflected signals.

Together with information on the receiver antenna position and the medium, the delay measurements associated with the properties of reflecting surface roughness parameters and to determine surface characteristics. Therefore the refracted, reflected and scattered GNSS signals can image the earth surface environments as a new highly precise, continuous allweather and near-real-time remote sensing tool which is expected to revolutionize various atmospheric sounding, ocean remote sensing and land/hydrology, 

mapping especially for various earth's surface and Simulation Table 1 atmosphere[7].

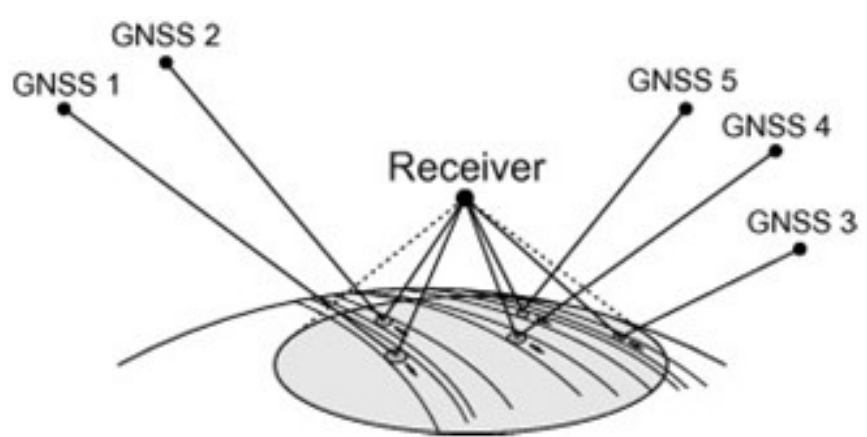

Figure 2: GNSS Reflectometry

\section{REVIEW OF RESEARCH PAPER}

Paper 1: Dual -wideband G-Shaped slotted printed monopole antenna for WLAN and WiMAX application. (IEEE 2013 W.N.W. Marzudi and Z. Z. Abidin)

In this paper G-shaped slotted printed rectangular monopole antenna with a deflected ground plane for band broadening is presented. This antenna achieved impedance bandwidth of $60.26 \%$ (over $2.4-4.47 \mathrm{GHz}$ ) and $28.04 \%$ ( over 4.6-6.1 GHz), with a reflection coefficient $<=-10 \mathrm{db}$. The obtained characteristic demonstrates that the proposed antenna is able to operate dual wideband frequency covering all the WLAN bands and WiMAX bands. The relative bandwidth for upper and lower frequency for proposed antenna with and without defected ground plane is summarized in Table 1. To clarify the response of the defected ground plane on the proposed antenna, the comparisons between the simulated reflection coefficient, $S_{11}$ with and without the defected ground plane are plotted in Fig 2.

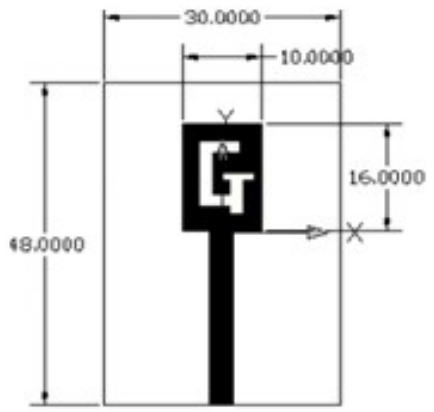

(a) Top view

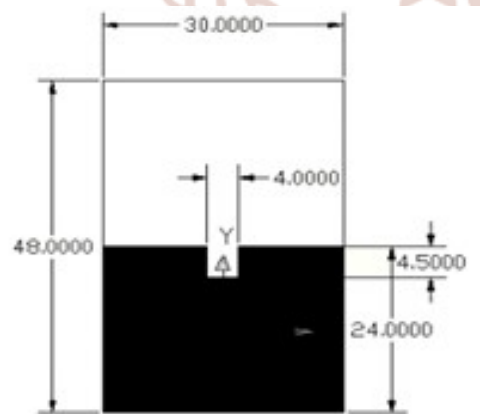

(b) Bottom view

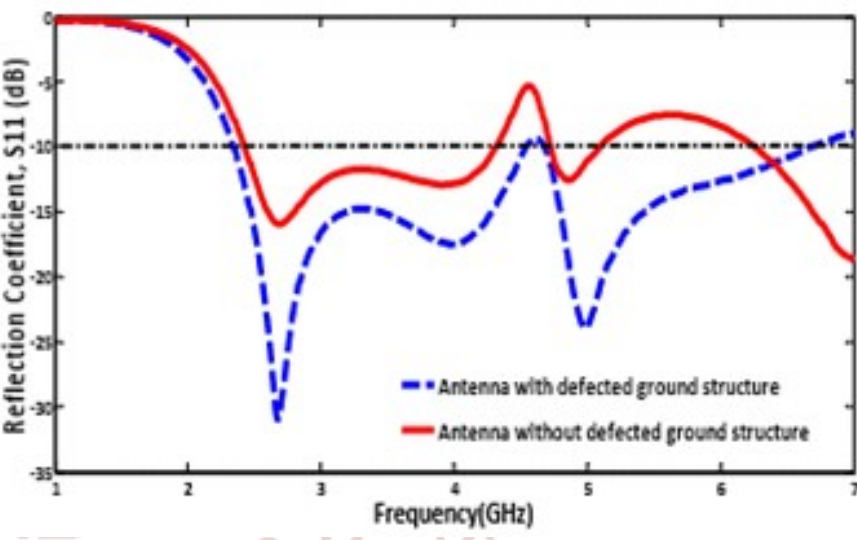

Fig 3 Simulated and measured reflection coefficient, $S_{11}$ of the proposed antenna.

PAPER 2:-Design of dual band microstrip patch antenna with defected ground plane for modern wireless application. (IEEE 2015 Imad Ali* ${ }^{\dagger}$ and Ronald Y. Chang)

In this paper, we design and analyze a dual-band rectangular microstrip patch antenna with defected ground plane for $2.5 \mathrm{GHz}$ and $3.5 \mathrm{GHz}$ communications. The proposed antenna provides wide impedance bandwidth of $13.56 \%(2.3-2.7 \mathrm{GHz})$ and $10.36 \%(3.3-3.7 \mathrm{GHz})$ at center frequencies of 2.5 $\mathrm{GHz}$ and $3.5 \mathrm{GHz}$ respectively. The gain in E-plane are $6.1 \mathrm{~dB}$ and $5.1 \mathrm{~dB}$ and the gain in $\mathrm{H}$-plane are 6.5 $\mathrm{dB}$ and 4.8 for $2.5 \mathrm{GHz}$ and $3.5 \mathrm{GHz}$ respect. The proposed dual band antenna shows monopole like radiation patterns with higher gain as compared to monopole antenna[4][6].

Fig. 2 : Geometry of the proposed antenna (in mm) (a) top view, and (b) bottom view 


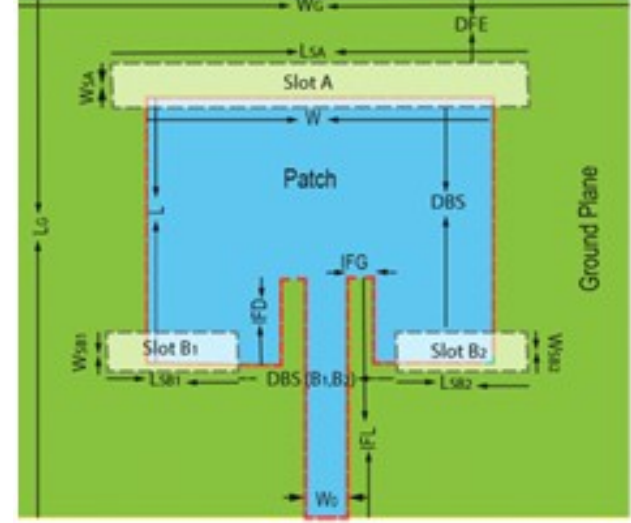

Fig. 4: Geometry of the proposed dual-band rectangular microstrip patch antenna

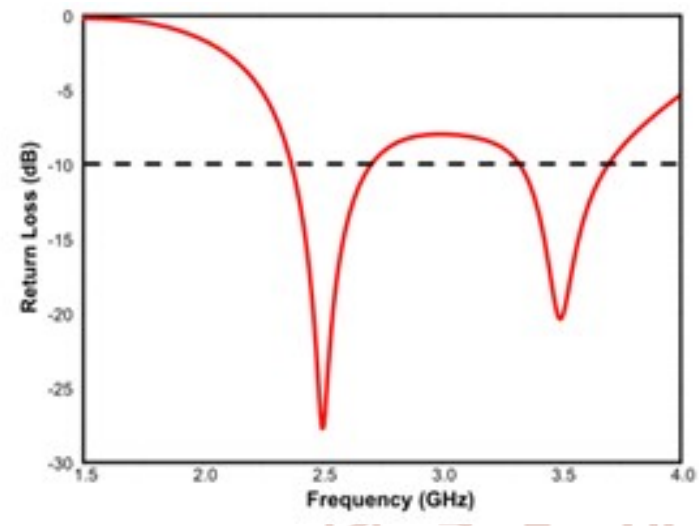

Fig. 5: Return loss
In this paper triple band is designed as one antenna for a dual-band $\mathrm{C} / \mathrm{X}$ with dual -linear polarization and a shared aperture antenna for single $\mathrm{Ku}$ band dual linear polarization behavior. Four different shapes of feeding ports for the two antenna provide good isolation among all frequencies at both polarization. The designed antenna exhibits stable frequency response at $\mathrm{ON} / \mathrm{OFF}$ states for either single/dual frequency selection or horizontal/vertical polarization. The result show fair radiation pattern with high gain.The proposed antenna provides good stability between ON/OFF states among the feeding ports, keeping the desired resonance frequency in case of single, and dual or even triple band operation unaffected. Fig. 7 shows the return loss when all the feed ports are in ON state (excited).

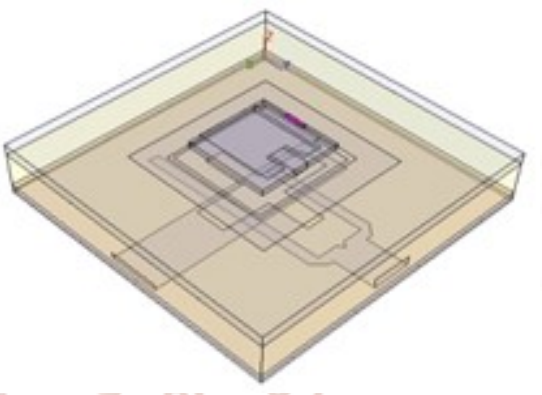

Fig 6: TBDP antenna element configuration

PAPER 3:-Design of triple -band dual linear polarized microstrip antenna sub- array for SAR applications. (IEEE 2014 Hossam Hamza, Biao Hou)

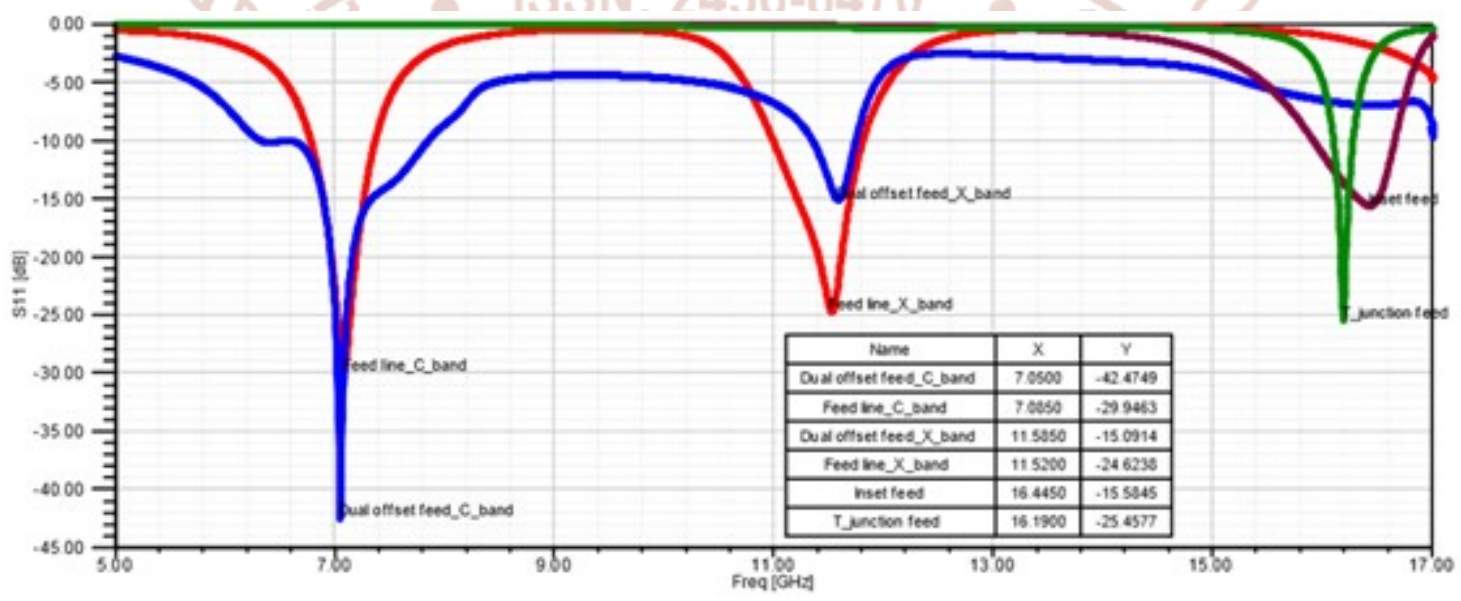

Fig 7: Return loss as all feeding lines are excited

PAPER 4:- Planner Tri-band antenna element in L/S/C band (IEEE 2017 J. Puskely, A. G. Yarovoy, A. G. Roederer)

In this paper planar Tri-band rectangle ring microstrip antenna design. The designed ring patch antenna element has good potential for application in tri-band wide scanning phased array. The antenna supports 3 sub-band are consistent radiation pattern with low level of cross-polarization in all sub-band. By adding vias we can tune the resonate process in case of infite/finite antenna array. 


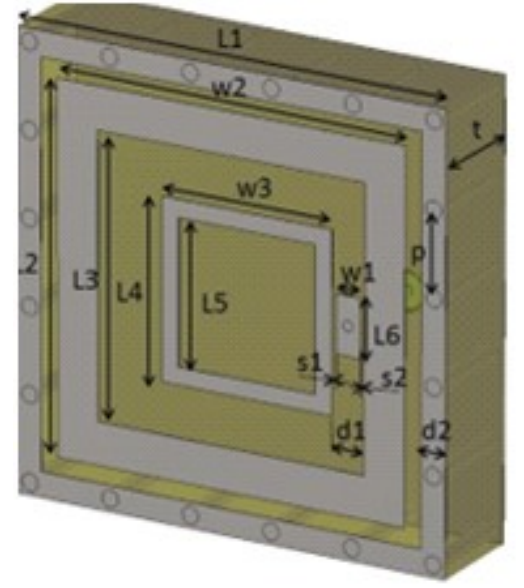

Fig 8: The geometry of the cavity tri-band microstrip rectangle-rings antenna

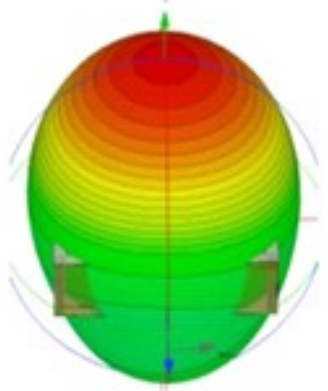

$4.82 \mathrm{dBi}$ at $1.45 \mathrm{GHz}$

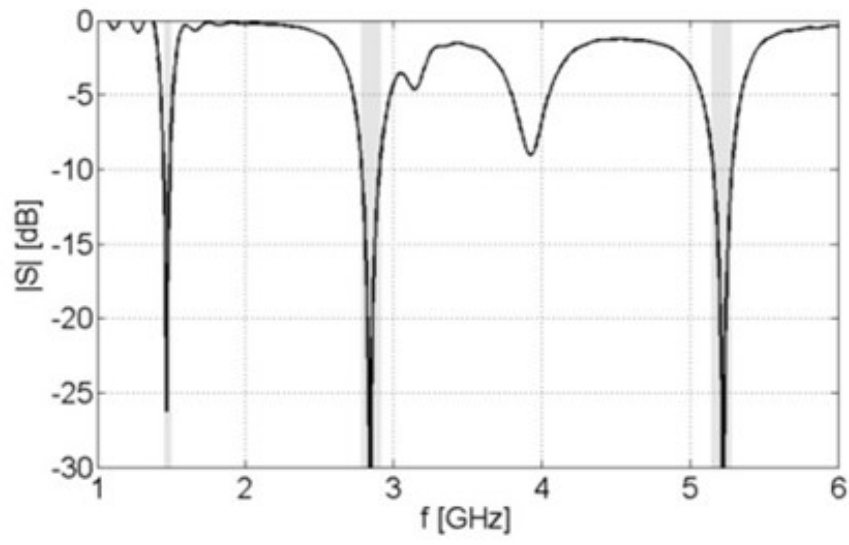

Fig 9: Computed input reflection coefficients of the tri-band patch antenna.

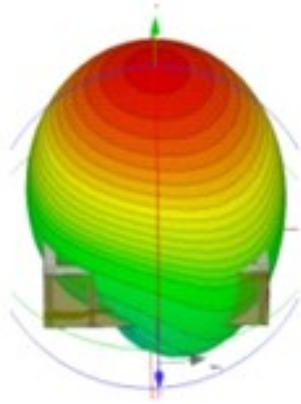

$6.5 \mathrm{dBi}$ at $2.85 \mathrm{Ghz}$

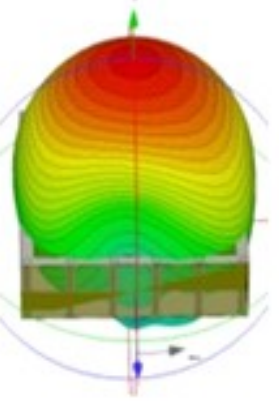

$8.3 \mathrm{dBi}$ at $5.25 \mathrm{GHz}$

Fig 10: Computed 3D radiation patterns at given resonance frequencies.

\begin{tabular}{|c|c|c|c|}
\hline $\begin{array}{l}\text { Sr. } \\
\text { No }\end{array}$ & Proposed Antenna & Technique Applied & Remarks \\
\hline 1. & $\begin{array}{l}\text { A G-shaped slotted printed } \\
\text { rectangular monopole antenna with } \\
\text { a defected ground plane for band } \\
\text { broadening is presented. }\end{array}$ & $\begin{array}{l}\text { It simply uses a G-shaped } \\
\text { slotted etched on the radiator } \\
\text { to achieve good dual-band } \\
\text { property. The defected ground } \\
\text { plane is applied to enhance the } \\
\text { impedance bandwidth of the } \\
\text { system. }\end{array}$ & $\begin{array}{l}\text { The proposed antena range } \\
\text { approximately from } 2.5 \text { to } 3.6 \\
\mathrm{dBi} \text { at } 2.4-2.5 \mathrm{GHz}, 3.1 \text { to } \\
3.6 \mathrm{dBi} \text { at } 3.5 \text { to } 5.2 \mathrm{GHz} \text { and } \\
2.2 \text { to } 2.4 \text { at } 5.5-5.8 \mathrm{GHz} \\
\text { respectively. }\end{array}$ \\
\hline 2. & $\begin{array}{l}\text { A dual-band rectangular microstrip } \\
\text { patch antenna antenna with defected } \\
\text { ground plane for } 2.5 \mathrm{GHz} \text { and } 3.5 \\
\text { GHz communications. }\end{array}$ & $\begin{array}{l}\text { The design concept is to have } \\
\text { two slots etched out from the } \\
\text { ground plane of a microstrip } \\
\text { patch antenna designed for } \\
2.5 \mathrm{GHz} \text { operation to enable } \\
\text { second frequency band ( } 3.5 \\
\text { GHz) operation. }\end{array}$ & $\begin{array}{l}\text { The proposed dual - band } \\
\text { antenna shows monopole-like } \\
\text { radiation patterns with higher } \\
\text { gains as compared to } \\
\text { monopole antenna. The gain } \\
\text { in E-plane are } 6.1 \mathrm{~dB} \text { and } \\
5.1 \mathrm{~dB} \text { and the gain in H-plane } \\
\text { are } 6.5 \mathrm{~dB} \text { and } 4.8 \text { for } 2.5 \\
\mathrm{GHz} \text { and } 3.5 \mathrm{GHz} \text { respect }\end{array}$ \\
\hline 3. & $\begin{array}{l}\text { A triple band is designed as one } \\
\text { antenna for a dual-band } \mathrm{C} / \mathrm{X} \text { with } \\
\text { dual -linear polarization and a } \\
\text { shared aperture antenna for single } \\
\mathrm{Ku} \text { band dual linear polarization }\end{array}$ & $\begin{array}{l}\text { Four different shapes of } \\
\text { feeding ports for the two } \\
\text { antenna provide good isolation } \\
\text { among all frequencies at both } \\
\text { polarization. }\end{array}$ & $\begin{array}{l}\text { The proposed antenna } \\
\text { provides good stability } \\
\text { between ON/OFF states } \\
\text { among the feeding ports, } \\
\text { keeping the desired resonance }\end{array}$ \\
\hline
\end{tabular}


International Journal of Trend in Scientific Research and Development (IJTSRD) ISSN: 2456-6470

\begin{tabular}{|c|c|c|c|}
\hline & behavior & & $\begin{array}{l}\text { frequency in case of single, } \\
\text { and dual or even triple band } \\
\text { operation unaffected. }\end{array}$ \\
\hline 4. & $\begin{array}{l}\text { A concept of tri-band microstrip } \\
\text { rectangle ring antenna for scanning } \\
\text { planar phased array is proposed }\end{array}$ & $\begin{array}{l}\text { The proposed antenna has a } \\
\text { planar, single-layer } \\
\text { architecture fed with a } \\
\text { standard SMA connector } \\
\text { model. EM coupled feed using } \\
\text { a small parasitic patch is } \\
\text { preferred here to be able fed } \\
\text { more than one element. }\end{array}$ & $\begin{array}{l}\text { The advantage of this design } \\
\text { is that there is space left inside } \\
\text { the ring to place another } \\
\text { smaller element to cover the } \\
\text { high frequency band also fed } \\
\text { by small parasitic patch. }\end{array}$ \\
\hline
\end{tabular}

\section{CONCLUSION}

Four papers for the design of multi-band microstrip antenna have been reviewed. First paper based on techniques such as etching of slot from the radiating element. However, these techniques hardly achieve the bandwidth requirement for multiband system. The second paper based on defected ground plane is used which produced wider bandwidth as compare to the radiation patch but due to the etching of slots create a defected in the ground plane of radiating patch, resulting in a disturbance to the shield current distribution in the ground plane and consequently the increased effective inductance and capacitance of the transmission line and the input impedance being affected. The third paper is based on Four different shapes of feeding ports for the two antenna provide good isolation among all frequencies at both polarization and fourth one is based on ring patch antenna element has good potential for application in tri-band wide scanning phased array. Each one has own merit and demerit one can select the suitable approach base on the application and requirement. From review of different research paper, we can conclude that by using ring patch antenna element has a good potential for the remote sensing application, the multi-band dual polarized array receives more target information as compared to single -band singlepolarization, and thus enhances the capability of target detection and identification.

\section{REFERENCES}

1. C.A. BALANIS, Antenna theory: analysis and design. John Wiley \& Sons, 2012

2. Imad Ali ${ }^{* \dagger}$ and Ronald Y. Chang "Design of dualband microstrip patch antenna with defected ground plane for modern wireless applications",IEEE 2015

3. W.N.W. Marzudi and Z. Z. Abidin"Dual wideband G-Shaped slotted printed monopole antennanzor WLAN and WiMAX application",IEEE 2013

4. Hossam Hamza, Biao Hou"Design of triple -band dual linear polarized microstrip antenna subarray for SAR applications, IEEE 2014

5. J. Puskely, A. G. Yarovoy, A. G. Roederer"Planner Tri-band antenna element in L/S/C band ",IEEE 2017

6. L.H. Weng, Y-C. Guo,X-W.Shi and X-Q.Chen," An overview on defected ground structure, "prog. Electromagn. Res, vol .7 pp.173-189,2008

7. Shuanggen Jin , Estel Cardellach ,Feiqin Xie" GNSS Remote Sensing Theory, Methods and Applications" 2014 